FORESHADOWING TARGETED VIOLENCE:

ASSESSING LEAKAGE OF INTENT BY PUBLIC MASS MURDERERS

\author{
Dr. James Silver* \\ Worcester State University \\ 486 Chandler Street \\ Worcester, MA 01602 \\ (508) 736-7419 \\ jsilver@worcester.edu
}

\author{
Dr. John Horgan \\ Georgia State University \\ Global Studies Institute \\ 25 Park Place, $17^{\text {th }}$ Floor \\ Atlanta, GA 30302 \\ (404) 413-6601 \\ jhorgan@gsu.edu
}

Dr. Paul Gill

University College London

35 Tavistock Square

London WC1H 9Z

02031083205

Paul.gill@ucl.ac.uk

*Corresponding Author 


\section{FORESHADOWING TARGETED VIOLENCE: ASSESSING LEAKAGE OF INTENT BY PUBLIC MASS MURDERERS}

\section{Highlights}

- Leakage of intent was present in more than half the sample of public mass murderers

- The most common form of leakage was statements to family and friends

- The only significant predictor of leakage was the presence of a grievance 


\title{
FORESHADOWING TARGETED VIOLENCE: ASSESSING LEAKAGE OF INTENT BY PUBLIC MASS MURDERERS ${ }^{1}$
}

\begin{abstract}
The idea that identifiable behaviors presage violence is a core concept in the threat assessment literature. Especially meaningful from an operational perspective is "leakage", which concerns whether offenders intentionally or unintentionally reveal insights into their thoughts or feelings that suggest impending targeted violence. Previous research has generally been limited to assessing the prevalence of leakage in various offender populations. The present study more thoroughly describes leakage in a sample of 115 public mass murderers in the U.S. whose activities took place between 1990 and 2014. We disaggregate leakage into three distinct forms (written statements, verbal statements to the public, verbal statements to family/friends), and examine these in relation to theorized correlates of leakage. The only significant predictor of leakage we found is the presence of a grievance, specifically a grievance against a person or entity, as opposed to a grievance against a category of people or a grievance against an idea, movement or religion. We discuss implications of these results as well as directions for future research.
\end{abstract}

Keywords: mass murder, leakage, grievance, threat assessment, targeted violence

\footnotetext{
${ }^{1}$ This research is supported by Award No. 2013-ZA-BX-0002, awarded by the National Institute of Justice, Office of Justice Programs, U.S. Department of Justice. The opinions, findings, and conclusions or recommendations expressed in this document are those of the authors and do not necessarily reflect those of the Department of Justice.
} 


\section{Introduction}

The idea that identifiable behaviors presage violence is a core concept in the threat assessment literature. These behaviors, sometimes called 'pre-event indicators' have also been referred to as "warning behaviors" (James et al., 2007, 2008), "signaling the attack" (Vossekuil, Reddy, Fein, Borum, \& Modzeleski, 2004), "high risk indicators” (Calhoun \& Weston, 2003), and "pre-attack signals" (Dietz \& Martell, 2010). Among the most important of these is "leakage" - i.e. the communication to a third party of intent to harm another (O'Toole, 2000; Meloy \& O’Toole, 2011). The information conveyed by leakage can encompass a range of factors, from objective details such as the target and location of the intended attack, to more subjective factors such as the motivation behind the impending violence.

While certain types of warning communications and behaviors had been described previously in relation to violent offenders, O'Toole (2000) first used the term "leakage" in her study of a sample of school shooters, describing it as occurring when a prospective offender "intentionally or unintentionally reveals clues to feelings, thoughts, fantasies, attitudes, or intentions that may signal an impending violent act. These clues could take the form of subtle threats, boasts, innuendos, predictions, or ultimatums. Clues could be spoken or conveyed in stories, diaries, essays, poems, letters, songs, drawings, doodles, tattoos, or videos" (p. 14).

Although based on slightly varying definitions of what constitutes communicated threats of potential violence toward a target, studies discussing leakage have examined its prevalence within various populations. Two studies specifically examined leakage among mass murderers. Hempel, Meloy and Richards (1999) assessed leakage in a sample of 30 adult mass murderers (defined as those who killed three or more). They divided what was termed a "threat variable" into four categories: a specific threat, made either verbally or in writing that described the 
impending attack, but which need not have been communicated to a third party; a generalized threat, which did not provide specific details of an attack and, again, need not be communicated to a third party; a mixed threat, which involved both a specific and a generalized threat; and, no threat. They found evidence of some type of threat in $67 \%$ of their cases.

In a 2001 study of 34 adolescent mass murderers (again, defined here as those who kill three or more), Meloy and colleagues found that in $44 \%$ of the cases the offender discussed the act of murder with at least one person prior to the event. They also found that in $58 \%$ of the cases where sufficient evidence was available for assessment (24 cases), offenders made threatening statements, generally to third parties (although it appears that some statements may have been made directly to targets).

Similar high levels of leakage have been found in various analogous offender types to mass murderers, although again definitions and interpretations of leakage differ from study to study. Fein and Vossekuil (1999) examined the behaviors of 83 persons known to have attacked or approached to attack public officials and public figures in the U.S. since 1949, finding that $63 \%$ of the offenders had made an indirect, conditional, or direct threat about the target, although only $11 \%$ had made a direct threat to the target or about the target to law enforcement. Vossekuil et al. (2004) examined 37 school-based attacks and 41 offenders for evidence that they "signaled" the attack, finding that in $81 \%$ of cases, at least one person had information that the offender was thinking about or planning the attack, and in $59 \%$ of the cases more than one person had information about the attack. Drysdale, Modzeleski and Simons (2010) studied 272 incidents of targeted violence at institutions of higher education occurring in the U.S. between 1900 and 2008 and determined that in $13 \%$ of the incidents $(n=35)$ the attacker made verbal and/or written threats about the target which were transmitted to the target or to a third party. 
Gill, Horgan, and Deckert (2014) examined 119 cases of those who engaged in or planned to engage in lone-actor terrorist attacks in the West. They found that in $64 \%$ of the cases the offender verbally told friends or family about the intent to engage in terrorist activity. They further found that in 59\% of cases, the offender made public statements prior to the planned attack.

Meloy and O'Toole (2011) re-examined the literature on leakage, concluding that progress had been hindered by the lack of a standardized definition. In pursuit of a more carefully delineated term, they re-oriented it over eight conceptually related warning behaviors that might precede incidents of targeted violence and be related to or perhaps even predictive of them:

1. Pathway warning behavior - behaviors that are part of research, planning, or preparation.

2. Fixation warning behavior - indications of an increasingly pathological preoccupation with a person or idea.

3. Identification warning behavior - behaviors that indicate a desire to be a "pseudocommando" or the like.

4. Novel aggression warning behavior - acts of violence unrelated to the attack behaviors that occur for the first time.

5. Energy burst warning behavior - an increase in the frequency of activities related to the target.

6. Leakage warning behavior - communication to a third party of intent to harm a target.

7. Directly communicated threat warning behavior - communication of a direct threat to a target or law enforcement. 
8. Last resort warning behavior - increasing desperation through declaration in word or act.

So, for example, leakage would not include threats made directly to a target or law enforcement; that behavior is considered "directly communicated threat warning behavior" (number 7), which, while obviously relevant to a threat assessment is rare compared to leakage (Meloy, Hoffman, Roshdi, Glaz-Ocik, \& Guldimann, 2014; Warren, Mullen, \& Ogloff, 2011). Leakage is also separate from "last resort warning behavior" (number 8) which, as the name suggests, involves behaviors which likely occur close in time to the attack and suggest that the individual has made a conscious determination that there is no alternative to violence. In contrast, leakage is a more general behavior that may be intentional or unintentional and is not constrained by temporal limitations.

As the citations above highlight, research on leakage is in its infancy. There has been some theorizing regarding its definition and boundaries but where empirical studies exist, they simply present leakage's prevalence. This paper aims to go a step further by drawing on a unique sample of 115 public mass murderers. First, we provide a disaggregated view of leakage’s different forms and how prevalent they are. Then, we investigate if anything differentiates those public mass murderers who leak from those who do not. We test a number of intuitive predictors of whether leakage occurs or not. The research findings are necessarily exploratory here as there is simply not enough existing research for formal hypothesis testing. The results provide operationally useful guidance on the nature of leakage in this offender population and, it is hoped, will spur similar investigative efforts into the role of this important warning sign in various other groups of violent offenders. 


\section{Method}

We obtained the data as part of a broader study into the demographics and behavioral underpinnings of public mass murderers in the United States (Horgan, Gill, Bouhana, Silver, \& Corner, 2016). We collected data from open source research on all identifiable offenders from 1990 to 2014 who met the study definition of public mass murderers. Open source research has been used in a variety of prior research, including studies regarding attempted assassinations of public officials, fatal school shootings, active shooter events, terrorism, and violence affecting institutions of higher learning (Drysdale et al., 2010; Fein \& Vossekuil, 1999; Gill et al., 2014; Lankford, 2012; 2015; Newman, Fox, Roth, Mehta \& Harding, 2004; Vossekuil et al., 2004).

Although there is general agreement that a mass murder occurs essentially in a single location over a short period of time, there is disagreement about the number of victims required to meet the definition of "mass murder." For reasons set forth by Gill et al. (2016) and summarized here, this study defines public mass murder as four or more homicide victims (not including the offender) killed at one location (or multiple but geographically close locations) within a short period, and excludes certain types of mass murder events. We acknowledge that the distinction between two or three victims on the one hand (or even some number of seriously injured victims) and four or more victims on the other hand is somewhat arbitrary, but believe that the higher threshold serves a practical purpose - separating multiple killings from more "routine" acts of homicide generally (Fox \& Levin, 1998). Furthermore, in mass murder studies such as the present one where data are collected via open source research methods, the number of victims is an important determinant of media coverage (Duwe, 2000, 2005). Additionally, four or more victims (not including the offender) served as the inclusion criteria adopted by the Federal Bureau of Investigation in its 2005 report: Serial Murder: Multi-Disciplinary 
Perspectives for Investigators, released after a meeting of experts in various fields relevant to the study of multiple homicides.

The study sample comprises all identifiable individuals who committed a public mass murder in the United States during the period 1990 to 2014. The study excludes mass murders that involve primarily intimate partner violence ("IPV") and occur in the home, as these are often treated in the literature as conceptually distinct from mass murders of non-family members and/or in public places (Holmes \& Holmes, 1992; Peete, Padget, \& York, 1997). Moreover, while Fox and Levin (2003) estimate that IPV mass murders comprise nearly half of all mass murders, the cases that generate the most media attention and therefore might most directly affect public policy take place in public settings and involve at least some victims who are not related to the offender (Duwe, 2004). Given the open source research method employed here, we thought it prudent to focus on those events most likely to yield usable data. Also excluded are deaths arising from gang and/or organized crime activities, as these types of events have historically not been studied as mass murders since practitioners generally see their motivations as distinct from those of the individuals discussed in the present study (Madfis, 2014). Finally, the sample excludes mass murders with more than one offender, as we designed the study to develop data suitable for comparison with existing samples of individuals who commit acts of targeted violence (such as lone offender terrorists).

To identify our sample, we first examined the academic literature on mass murderers, producing a list of names that fit our criteria. We located additional offenders through databases created by Mother Jones, USA Today, and Mayors Against Illegal Guns as well as by conducting tailored searches using specific terms on LexisNexis and other search engines. Finally, we searched the Federal Bureau of Investigations Supplementary Homicide Reports for the relevant 
years to identify offenders who may not have been captured by our other sources. Ultimately, 115 offenders met the specified inclusion/exclusion criteria. While there is no way to know if we found every public mass murderer who fit our parameters, we are confident that we found the overwhelming majority as our dataset is very much in line with recent comparable research. Using definitions like ours, and gathering data primarily from the Federal Bureau of Investigations Supplementary Homicide Reports, Krouse and Richardson (2015) identified 66 mass public shootings (with four or more killed) over a 15-year period (1999-2013; 4.4 events per year). During that same 15-year period, we found 88 public mass murders (1999-2013; 5.9 events per year), and over the longer 25-year period of our study, we found 115 public mass murders (1990-2014; 4.6 events per year) (although nine mass murderers in our sample used a weapon other than a firearm).

\subsection{Codebook}

We created a codebook for data collection after an extensive review of the literature on individuals who committed offenses along the wide spectrum of violent crimes, including murder, as well as those who engage in other forms of high-risk behaviors. We also reviewed other codebooks developed for the construction of terrorism and active shooter data bases used in academic research or maintained by law enforcement (e.g., the FBI Active Shooter Database). The codebook contains more than 180 variables (many with sub-parts) covering four major areas of theoretical interest: demographic, antecedent event behavior, event specific behavior, and, if the offender survived the event, post-event behavior.

Three separate coders independently coded each observation and we reconciled their results in two ways. First, we reconciled each coder's work with that of the other two coders. In 
cases of disagreement on a specific variable, the project manager, who reviewed all coding for each offender, determined the appropriate response. As part of this second-stage reconciliation, the project manager took into consideration the trustworthiness of the sources relied upon by the coders (e.g., records of court proceedings were viewed as more reliable than media reports collected immediately after the event) as well as the specific information contained in the source (e.g., official statements from law enforcement officials versus statements by those merely acquainted with the offender).

\subsection{Analysis}

We measured leakage using three variables that encompass the universe of communications by these offenders of intent to do harm to a target, including oral communication, voice mails, writings, mail, email, Internet communications (e.g., blogs, chats), and texts. There were no instances of visual manifestations (e.g., tattoos, drawings) in our sample. The three variables are:

1. Written Statements - public written statements (including on social media) about his or her intent or beliefs prior to the event;

2. Verbal Statements Public - verbal statements about his or her intent or beliefs to a nonfamily member/friend prior to the event;

3. Verbal Statements Family/Friends - verbal statements about his or her intent or beliefs to family or friends prior to the event.

First, we described both the prevalence and the nature of the three types of leakage. Next, we aggregated the three types of leakage into a "global leakage" variable which measures whether the offender engaged in leakage of any kind, making no distinction among means of 
communication. We analyzed this global leakage variable (coded as "yes/no") through a series of crosstabs along variables of theoretic interest (e.g., demographic categories, the presence of a mental health history, the presence of a grievance, social isolation). Finally, we conducted a logistic regression of global leakage and each of the three sub-types of leakage (individually coded as "yes/no") along variables found to be significant in the bivariate analysis. As the inquiry into possible correlates of leakage has not before been undertaken, there is little research to guide the analysis. Therefore, we assessed leakage relative to as wide a range of potentially relevant variables as possible, with the goal of establishing a baseline that can be refined and improved by future efforts. We separated these predictor variables into categories based on theoretical considerations and assumed practical relevance.

Of note, it is often difficult to distinguish between missing data and variables that should be coded as a 'no'. Given the nature of newspaper and media reporting, it is unrealistic to expect that stories focused on the immediate aftermath of extreme violence would address each of the many variables contained in this study. Therefore, it is probable that we significantly undercounted "no" answers in the data (i.e., news accounts simply do not address all - or even the majority - of the behaviors that an offender did not engage in, resulting in missing data). To address this issue, in many of the analyses herein, we treat each variable as dichotomous (either "yes" or "not enough information to suggest a yes"). The approach has been used in prior research on targeted violence affecting institutions of higher education, attempted assassinations of public figures, lone offender terrorists, and fatal school shootings, and (Drysdale et al., 2010; Fein \& Vossekuil, 1999; Gill et al., 2014; Vossekuil et al., 2004). 


\section{Results}

\subsection{Descriptive Results}

We consider leakage within the framework suggested by Meloy and O'Toole (2011) and define leakage as communication to a third party of an intention to harm a target, with means of "communication" and "target" interpreted broadly to capture even indistinct signals of violent ideation. In measuring leakage, we were cognizant of the roots of the concept, where the aim is to identify facts that would be of use to a threat assessment professional or law enforcement officer in assessing the potential for violence. As conceived in prior research and as applied here, leakage need not be contemporaneously recognized by others as a sign of impending violence, let alone mass murder, to be relevant. In some cases, it is only in retrospect that the significance of a communication is understood. Nor is the purpose here to evaluate reasons why third parties may not have seen the significance of any leakage or why they did not contact appropriate persons when they did interpret leakage as a sign of impending violence. The focus here is on what types of leakage behaviors were known or were knowable at the time and which might have proved relevant in a threat inquiry. With that in mind, though, we were sensitive to the possibility of overinclusion and were careful to avoid assigning significance to any communication that could rationally only be seen as benign at the time it was made.

We found leakage of some sort in more than half of the sample ( $n=67,58.3 \%)$, with some offenders exhibiting more than one type of leakage. This percentage is generally in line with prior findings that more than half of offenders engage in some form of leakage. Here, the leakage was often related to the eventual victims of the public mass murderer. In some cases, though, the message described a fascination with or desire to use violence generally, or even a vaguely defined urge for revenge against unnamed persons or entities. Generally, the leaked 
intent could be derived from the words (written or spoken) themselves, but in some instances ancillary factors such as the timing and/or audience for a written statement or the tone and/or the context for a verbal statement provided additional evidence of the possible intent to commit violence against another.

\subsubsection{Written statements}

The least common means of leakage was the offender making some type of written communication $(n=14)$. These disclosures were made in various forms to diverse audiences. In the weeks prior to killing 22 people (14 of whom were women) at a local restaurant, George Hennard wrote a letter to two sisters he barely knew in which he angrily described the area woman as "vipers" who were trying to destroy him. Bryan Uyesugi's co-workers at the Xerox office in Honolulu became worried when, among other things, he began leaving threatening notes for some of them. Uyesugi subsequently opened fire at work, killing six co-workers and a supervisor. Jaylen Fryberg tweeted about his anger at an unnamed person (likely his cousin who was dating a girl Fryberg liked), and texted a series of ominous notes to his ex-girlfriend about being distraught and having a gun in his hand. Minutes before opening fire and shooting among others, his cousin, Fryberg sent a photo of a gun in his lap to a friend.

Some of the written communications were short and relatively simple, while others were decidedly longer and less rational. In Facebook posts made days before he killed five people, Shayne Riggleman succinctly expressed his disappointment at being rejected by the military and his thoughts about revenge. In contrast, Jared Loughner made a rambling series of seemingly nonsensical Internet posts about government conspiracies, suicide, grammar, and killing police 
officers before eventually killing six in his attack on Representative Gabrielle Giffords at her public meeting with constituents.

\subsubsection{Verbal statements public}

Verbal leakage to the public (persons excluding family and close friends) was far more common than written leakage. Thirty-five offenders said things that suggested an intention to commit violence. Some of the statements seemed to have been made almost unconsciously. While purchasing ammunition at a Walmart store, Herbert Chalmers was overheard saying (presumably to himself) that he was going to kill his boss, which he did. Other statements were

much plainly meant to be heard. Thomas McIlvane joked with colleagues about the mass murder in Killeen, Texas (committed by George Hennard, referenced above in section 3.1.1) and said that the same thing would happen if he wasn't reinstated after his arbitration hearing; after losing the hearing he returned to the post office from which he had been fired a year earlier and killed four people. Nathan Dunlop made numerous public statements to acquaintances about killing people and robbing the restaurant from which he had recently been fired, and then did exactly that.

Although $68.6 \%$ of verbal statements to the public concerned identifiable persons $(n=24)$, not all were linked to specific targets who could have been known prior to the attack. Before killing 12 victims at a movie theater, James Holmes spoke to fellow students about his desire to kill "people" and made similar comments to the psychiatrist who was treating him. Floyd Zane told a prostitute whom he had just raped in his apartment that he wanted to kill the next people he saw. Zane then walked with his shotgun to a nearby supermarket and killed four strangers. Not all verbal communications were specifically about killing. Some were statements that 
conveyed menace as much by the delivery than the actual words. On numerous occasions Charles Thornton disrupted city council meetings with angry outbursts about how he was being unfairly targeted for enforcement of certain ordinances. He eventually stormed one such meeting and killed five people.

\subsubsection{Verbal statements family/friends}

The most common form of leakage was verbal statements to family or friends $(n=36)$. In several instances offenders directly revealed their plans in these communications. Charles Brownlow called his family and announced his plan to kill many of them. Two days later he killed four of those family members, including his mother and aunt, as well as one stranger. While assaulting an ex-girlfriend, Herbert Chalmers (the same man mentioned in section 3.1.2 who was overheard at Walmart threatening to kill his boss) told her that he was going to kill everyone who had made him suffer in his life. He subsequently killed four people including the mother of his child and two people at a company where he once worked. Prior to killing four people at the high school from which he graduated four years before, Eric Houston talked with his best friend about wanting to kill people at that school, including one teacher who had given him a failing grade in a class.

As with other forms of leakage, not all verbal statements to friends and family were direct declarations of the intention to kill others. Before killing his parents at his home and then students at his school, fifteen-year-old Kip Kinkel made a series of troubling statements to his friends; he often said that it would be fun to kill someone, bragged about torturing animals, and described his expertise with explosives and weapons. The day before he killed four people at a 
social services office, John Miller had been at that same office complaining that a child-support order was ruining his life and threatening to kill himself.

\subsection{Bivariate analysis}

Age, birthplace, education, employment, military service, criminal history

We divide age into six categories intended to capture potential variations related to social connections (e.g., employment, romantic relationships) and methods of communication (e.g., use of social media) that might be based on relatively discrete age differences. Place of birth measures whether the offender was born outside the United States, as immigrant status could influence social integration. Education and occupational categories may present differential opportunities to give signals to third-parties and may also be related to the offender's willingness to communicate the intent to commit violence based on the perceived reaction of colleagues and the sophistication of the offender's analytic skills. Military service and training may influence the offender's level of comfort with weapons and violence. Offender criminal history, shown by adult arrest, conviction and incarceration, is a measurement of experience in the criminal justice system which may reflect an offender's inability to exercise self-control as well as a willingness to engage in inappropriate behaviors - such as indicating a desire to engage in violence. 
TABLE 1: Leakage by Age, Education, Employment, Military and Criminal History

\begin{tabular}{|c|c|c|}
\hline $\begin{array}{l}\text { Did the offender exhibit any } \\
\text { behavioral leakage? }\end{array}$ & $\begin{array}{l}\text { Yes } \\
(\mathrm{n}) \\
\end{array}$ & $\begin{array}{l}\text { No } \\
\text { (n) } \\
\end{array}$ \\
\hline Age 14-19 & (7) $10.4 \%$ & (2) $4.2 \%$ \\
\hline Age 20-29 & (19) $28.4 \%$ & (17) $35.4 \%$ \\
\hline Age $30-39$ & (17) $25.4 \%$ & (12) $25 \%$ \\
\hline Age $40-49$ & (17) $25.4 \%$ & (10) $20.8 \%$ \\
\hline Age 50-59 & (7) $10.4 \%$ & (5) $10.4 \%$ \\
\hline Age 60+ & (0) $0.0 \%$ & (2) $4.2 \%$ \\
\hline Place of Birth & (14) $20.9 \%$ & (8) $16.7 \%$ \\
\hline High School & (21) $31.3 \%$ & (15) $31.3 \%$ \\
\hline Some College & (16) $23.9 \%$ & (9) $18.8 \%$ \\
\hline Graduated College & (3) $4.5 \%$ & (2) $4.2 \%$ \\
\hline Graduate School & (3) $4.5 \%$ & (1) $2.1 \%$ \\
\hline Unemployed & (20) $29.9 \%$ & (12) $25.0 \%$ \\
\hline Student & (7) $10.4 \%$ & (3) $6.3 \%$ \\
\hline Service Industry & (16) $23.9 \%$ & (17) $35.4 \%$ \\
\hline Professional & (4) $6.0 \%$ & (2) $4.2 \%$ \\
\hline Construction & (5) $7.5 \%$ & (2) $4.2 \%$ \\
\hline Clerical/Sales & (2) $3.0 \%$ & (1) $2.1 \%$ \\
\hline Other & (5) $7.5 \%$ & (7) $14.6 \%$ \\
\hline Military Service & (13) $19.4 \%$ & (8) $16.7 \%$ \\
\hline Arrest & (36) $53.7 \%$ & (28) $58.3 \%$ \\
\hline Conviction & (28) $41.8 \%$ & (21) $43.8 \%$ \\
\hline Incarceration & (17) $25.4 \%$ & (14) $29.2 \%$ \\
\hline
\end{tabular}

None of these variables were significant at any level.

Social connection and mental health

Leakage occurs only with some level social interaction, no matter how inconsequential even unintentional leakage occurs through at least minimal contact with another person - and the differential possibilities of interacting with third-parties are measured here by whether the offender is socially isolated and whether the offender lived alone. As shown in Table 2, neither 
variable has a statistically significant relationship with leakage. Offenders with mental illness and substance abuse issues might plausibly be less able to regulate their communications and more likely than those without such issues to leak the intent to commit violence. Substance abuse does not have a statistically significant relationship with leakage, while mental illness is significant at the 0.1 level.

TABLE 2: Leakage by Social Connection and Mental Health

\begin{tabular}{lcc}
\hline $\begin{array}{l}\text { Did the offender exhibit any } \\
\text { behavioral leakage? }\end{array}$ & $\begin{array}{l}\text { Yes } \\
(\mathrm{n})\end{array}$ & $\begin{array}{l}\text { No } \\
(\mathrm{n})\end{array}$ \\
\hline Socially Isolated & $(19) 28.4 \%$ & $(11) 22.9 \%$ \\
Lived Alone & $(15) 22.4 \%$ & $(13) 27.1 \%$ \\
Mental Illness* & $(27) 40.3 \%$ & $(27) 56.3 \%$ \\
Substance Abuse & $(31) 46.3 \%$ & (20) $41.7 \%$ \\
\hline
\end{tabular}

$*=\mathrm{p}<.1, * *=\mathrm{p}<.05, * * *=\mathrm{p}<.01$

\section{Stressors and Grievance}

The various experiences and behaviors listed in Table 3 are assumed to negatively affect important areas of an offender's life, leading to circumstances that might cause the offender to respond with violence and potentially leak that intent pre-event. Some stressors, such as not care (someone important to the offender indicating a lack of concern for the offender), relationship (problems with existing close personal relationships) and degraded (the feeling of being treated without appropriate respect, especially in public settings) are based on the offender's inner life. Work related and financial have a more objective foundation, while anger, long term stress and recent stress measure factors not covered by other stress variables. Tipping point indicates whether the offender has had some experience near in time to the event that appears to have had a direct effect on the offender's movement toward violence (e.g., some cause for distress). 
Related to the notion of stressor is grievance which has been incorporated into a behavioral pathway model conceptualized in two US Secret Service studies, one involving assassinations of public figures and the other school shootings (Fein \& Vossekuil, 1999; Vossekuil et al., 2004). These (and following studies) theorized a route from idea to violent action comprising ideation, planning, preparation and implementation. These same phases were incorporated into a model of a "pathway to violence" (Calhoun \& Weston, 2003), which proposes six milestones on the trajectory: grievance, ideation, research and planning, preparation, breach and attack.

In the threat assessment literature in which the pathway to violence model arose, a grievance is defined as the cause of the offender's distress or resentment, a perception of having been treated unfairly or inappropriately. More than a feeling of anger, a grievance often results in a desire, even a sense of mission, to right the wrong and achieve a measure of deserved justice (Calhoun \& Weston, 2003; Fein \& Vossekuil, 1999; Vossekuil et al., 2004). A grievance is a subjective experience that need not have any objective foundation and can arise from actual slights and defeats, imagined wrongs, mental illness or some combination of these factors. Characteristic of a grievance is that the offender attributes his or her own distress to an external source, something beyond the offender that has acted or is acting unfairly against the offender.

We also disaggregated grievance into three categories: grievance person/entity (e.g., against a supervisor, governmental agency); grievance category (e.g., against a race, ethnicity or gender); and, grievance idea (e.g., grievance against an idea, movement or religion). Evidence of grievance came generally from the offender's own words and writings, in some cases supplemented by observations from those who knew the offender well. In 73 cases (63\%) the offender had a grievance. In 65 of the grievance cases (89\%), the grievance was against a 
specific person or entity, in 18 cases (24.6\%), the grievance was against a category of people, and in 8 cases (10.9\%), the grievance was against an idea, movement or religion ( 9 offenders had two types of grievance, and 4 offenders had all three types of grievance). As shown in Table 3, grievance $(\mathrm{p}=.003 ; \mathrm{Phi}=.274)$ and grievance person/entity $(\mathrm{p}=.002 ; \mathrm{Phi}=.289)$ are significant.

TABLE 3: Leakage by Stressors and Grievance

\begin{tabular}{lcc}
\hline $\begin{array}{l}\text { Did the offender exhibit any } \\
\text { behavioral leakage? }\end{array}$ & $\begin{array}{l}\text { Yes } \\
\text { (n) }\end{array}$ & $\begin{array}{c}\text { No } \\
(\mathrm{n})\end{array}$ \\
\hline Work Related & $(31) 46.3 \%$ & $(25) 52.1 \%$ \\
Degraded & $(25) 37.3 \%$ & $(20) 41.7 \%$ \\
Not Care & $(15) 22.4 \%$ & $(16) 33.3 \%$ \\
Relationship & $(39) 58.2 \%$ & $(32) 66.7 \%$ \\
Financial & $(21) 31.3 \%$ & $(19) 39.6 \%$ \\
Angry & $(45) 67.2 \%$ & $(32) 66.7 \%$ \\
Long Term Stress & $(40) 59.7 \%$ & $(32) 66.7 \%$ \\
Recent Stress & $(37) 55.2 \%$ & $(28) 58.3 \%$ \\
Tipping Point & $(28) 41.8 \%$ & $(22) 45.8 \%$ \\
Grievance*** & $(50) 74.6 \%$ & $(23) 47.9 \%$ \\
Grievance Person/Entity*** & $(46) 68.7 \%$ & $(19) 39.6 \%$ \\
Grievance Category & $(12) 17.9 \%$ & $(6) 12.5 \%$ \\
Grievance Idea & $(5) 7.5 \%$ & $(3) 6.3 \%$ \\
\hline \multicolumn{2}{c}{$* \mathrm{p}<.1, * *=\mathrm{p}<.05, * * *=\mathrm{p}<.01 ;$ Fishers exact test }
\end{tabular}

Event

Certain characteristics of the event itself are theorized to potentially relate to leakage.

Having a discriminate target (specific person(s) identifiable prior to the attack) implies the offender consciously spent some time choosing a target and planning an attack on that specific target, providing at least a minimal period during which leakage about that target might occur. A history with the location of the attack (familiarity from having worked, lived or frequented the attack site) suggests a connection with the attack site that could lead the offender to have leaked 
the intent to commit violence to persons also associated with that site. Choice of weapon might also be related to leakage: obtaining a firearm might entail communication with a dealer, licensing agency or even private seller; building an explosive device might necessitate seeking technical advice. As shown in Table 4, the only event variable with a significant relationship with leakage was arson $(\mathrm{p}=.031 ; \mathrm{Phi}=.199)$.

TABLE 4: Leakage by Event

\begin{tabular}{lcc}
\hline $\begin{array}{l}\text { Did the offender exhibit any } \\
\text { behavioral leakage? }\end{array}$ & $\begin{array}{c}\text { Yes } \\
(\mathrm{n})\end{array}$ & $\begin{array}{c}\text { No } \\
(\mathrm{n})\end{array}$ \\
\hline Discriminate Target & $(52) 77.6 \%$ & $(39) 81.3 \%$ \\
History/Location & $(50) 74.6 \%$ & $(41) 85.4 \%$ \\
Bombing & $(2) 3.0 \%$ & $(0) 0.0 \%$ \\
Shooting & $(61) 91 \%$ & $(46) 95.8 \%$ \\
Stabbing & $(7) 10.4 \%$ & $(4) 8.3 \%$ \\
Arson $* *$ & $(9) 13.4 \%$ & $(1) 2.1 \%$ \\
Other Weapon & $(5) 4.5 \%$ & $(2) 4.2 \%$ \\
\hline \multirow{2}{c}{$*=\mathrm{p}<.1, * *=\mathrm{p}<.05, * * *=\mathrm{p}<.01 ;$} & Fishers exact test
\end{tabular}

\subsection{Logistic regression}

Logistic regressions were performed using the three variables with statistically significant relationships to leakage: grievance person/entity, mental illness and arson. First, the variables were regressed against global leakage (the presence of leakage of any kind):

TABLE 5: Global Leakage

\begin{tabular}{|l|c|c|c|c|c|c|}
\hline & B & Wald & Sig. & Exp(B) & \multicolumn{2}{|c|}{$\begin{array}{c}\text { L5\% C.I Exp (B) } \\
\text { Lower }\end{array}$} \\
\hline Griev. person/entity & 1.322 & 9.953 & .002 & 3.749 & 1.650 & 8.521 \\
\hline Mental Illness & -.397 & .924 & .336 & .672 & .299 & 1.510 \\
\hline Arson & 2.308 & 4.369 & .037 & 10.056 & 1.155 & 87.573 \\
\hline
\end{tabular}

Note: Nagelkerke $\mathrm{R}^{2}=.196, x^{2}=18.071, \mathrm{p}<.001$ 
The same independent variables were then regressed against each of the three types of leakage that compose the global leakage measurement:

TABLE 6: Written Statements

\begin{tabular}{|l|c|c|c|c|c|c|}
\hline & B & Wald & Sig. & $\operatorname{Exp}(\mathrm{B})$ & \multicolumn{2}{|c|}{$95 \%$ C.I Exp (B) } \\
& & & & Lower & Upper \\
\hline Griev. person/entity & 1.148 & 2.732 & .098 & 3.151 & .808 & 12.293 \\
\hline Mental Illness & .251 & .180 & .671 & 1.285 & .404 & 4.090 \\
\hline Arson & -19.087 & .000 & .999 & .000 & .000 & \\
\hline
\end{tabular}

Note: Nagelkerke $\mathrm{R}^{2}=.095, x^{2}=5.892, \mathrm{p}=.117$

TABLE 7: Verbal Family/Friends

\begin{tabular}{|l|c|c|c|c|c|c|}
\hline & B & Wald & Sig. & $\operatorname{Exp(B)}$ & \multicolumn{2}{|c|}{$\begin{array}{c}\text { 95\% C.I Exp (B) } \\
\text { Lower }\end{array}$} \\
\hline Griev. person/entity & .248 & .351 & .554 & 1.281 & .564 & 2.911 \\
\hline Mental Illness & .024 & .003 & .954 & 1.024 & .456 & 2.298 \\
\hline Arson & -.603 & .532 & .466 & .547 & .108 & 2.764 \\
\hline
\end{tabular}

Note: Nagelkerke $\mathrm{R}^{2}=.013, x^{2}=1.057, \mathrm{p}=.787$

TABLE 8: Verbal Public

\begin{tabular}{|l|c|c|c|c|c|c|}
\hline & B & Wald & Sig. & Exp(B) & \multicolumn{2}{|c|}{$\begin{array}{c}95 \% \text { C.I Exp (B) } \\
\text { Lower }\end{array}$} \\
\hline Griev. person/entity & .291 & .472 & .492 & 1.338 & .583 & 3.067 \\
\hline Mental Illness & .478 & 1.308 & .253 & 1.612 & .711 & 3.655 \\
\hline Arson & .119 & .026 & .871 & 1.127 & .266 & 4.773 \\
\hline
\end{tabular}

Note: Nagelkerke $\mathrm{R}^{2}=.019, x^{2}=1.567, \mathrm{p}=.667$ 
The only significant relationship was global leakage with grievance person/entity and arson. Offenders who had a grievance against a person or entity were 3.8 times as likely to engage in some form of leakage as were those without a grievance against a person or entity. The findings regarding arson should be interpreted with caution, as there were only 10 cases of arson in the sample.

\section{Discussion}

The notion of leakage is somewhat paradoxical because of its inherently counterproductive nature - alerting (albeit, sometimes unintentionally) third parties to a potential criminal act invites a response that could end or diminish the possibility of the intended violence. Nevertheless, leakage is apparent across all targeted violence offender groups where it has been studied (juvenile mass murderers, adult mass murderers, attackers of public figures, school shooters, and lone actor terrorists). We provide further evidence via our findings. Additionally, however, comparison of our results with findings from prior mass murder samples is useful, especially since the sample here is over three times larger than each of the prior reported samples. Leakage was present in $58.3 \%$ of the 115 public mass murderers in the present sample, a percentage slightly lower than the $67 \%$ in a prior sample of 30 adult mass murderers (Hempel et al., 1999), and nearly identical to the $58 \%$ of a sample of 34 adolescent mass murderers (Meloy et al., 2001).

Of course, finding leakage is one thing, determining its operational utility another. The goal is to separate the wheat from the chaff, distinguish markers of impending violence from innocuous statements, ambiguously phrased comments, or indications of transitory emotion. As Meloy and O'Toole (2011) noted, efforts to do that sifting will be aided greatly by research 
assessing the predictive validity of leakage. This study, comparing public mass murder events where leakage occurred with events where leakage did not occur (false negatives), is a first step in that direction.

The results here are intriguing both for what they do not show as well as what they do. Several factors that intuitively might seem to be related to leakage turn out not to be significant social isolation and living alone have no meaningful effect on the presence of leakage, nor does mental illness or a wide variety of demographic factors and stressors. In short, there does not appear to be a "profile" of a lone public mass murderer more likely than others to leak intent prior to an act of targeted violence. Concerning at least lone public mass murderers then, this suggests two things: threat assessment professionals should not expect leakage based on a subject type (e.g., a young, socially well-connected person with a criminal history) and be reassured by its absence; nor should they be surprised by its presence with a subject type (e.g., a single, well-educated professional with no criminal record) and discount its potential significance.

While perhaps surprising that factors such as isolation, criminal history and age are not significant, the fact that a grievance against a person or entity is strongly correlated with leakage is understandable when considered in the context of the definition of grievance - the cause of the offender's distress or resentment, a perception of having been wronged or treated unfairly or inappropriately. More than a feeling of anger, a grievance often results in a desire, even a sense of mission, to right the wrong and achieve a measure of deserved justice. As conceived here (and generally in the threat assessment literature), a grievance is more than a momentary feeling of discontent or a short-lived, even explosive, expression of anger or frustration; rather, it is a conclusion reached about the reason for the offender's suffering (or the 
suffering of others about whom the offender cares). A grievance is external to the offender, and by externalizing blame - whether based on objectively accurate perceptions of circumstances or not - the offender necessarily creates a target for retribution. In effect, the grievance becomes an organizing principle as the offender seeks to address the unjust treatment causing the anguish.

Given its seeming centrality in the offenders' lives, it is understandable that they would speak or write about their grievances, and, intentionally or not, reveal clues about their intentions toward the causes of their unjust suffering. That grievance category and grievance idea do not correlate with an increase in leakage suggests that the phenomenon is a function of concreteness - a tangible, identifiable object to which causation of suffering can be ascribed. Perhaps offenders simply find it easier to communicate about a person or entity such as a government agency than they do a less well-defined subject such as category of people or an idea or philosophy, and the more amorphous the subject of the grievance, the less likely there is to be leakage concerning it. Or, it may be that others in the offender's social sphere are likewise familiar with the person or entity and this shared experience organically generates communication about the commonality.

\section{Limitations}

Certain limitations are inherent in the open source research method used here. While we made every effort to identify all offenders who met our inclusion/exclusion criteria, we may have missed some events. Also, media reporting typically does not address all the myriad biographical details relevant to researchers. Although we selected variables presumably of interest to the public and of the type we could reasonably expect the media cover, no sources exhaustively listed experiences the offender did not have (e.g., the offender was never 
unemployed), or behaviors the offender did not engage in (e.g., the offender did not engage in dry runs prior to the event). A related limitation is the variability of coverage in mass murder events. Research has suggested that the attention given to any mass murder by the media is affected by certain factors, and high-profile mass murders are significantly more likely to involve larger numbers of killed and wounded, stranger victims, public locations, assault weapons, and workplace violence (Duwe, 2000, 2005). The overall effect of such factors may mean that the amount of data available for certain offenders varies in a systematic way which may undermine the validity of our findings.

\section{Conclusion}

As of now there are no clear answers as to why leakage occurs. In truth, there are likely multiple motivations for leakage, ranging from seeking attention, the desire to intimidate, a need for excitement or the simple inability to contain anxiety related to the impending violent act (Meloy \& O'Toole, 2011). Regardless of motivation(s), though, the findings here suggest that those tasked with assessing potential violent offenders should be aware that leakage in its various forms is common among public mass murderers, although not universal, and consider the presence or absence of leakage with the understanding that it is most likely to occur when the offender has a grievance and that grievance is against a specific person or entity.

Importantly, the pathway to violence model does not suggest that all, or even many, people with a grievance will move toward violent action. As conceived in the pathway to violence model, those who become violent move beyond grievance to "ideation", the stage where they realize that violence is the appropriate means to address the grievance and make a conscious choice to cause harm to others (Calhoun \& Weston, 2003). While our study does not 
address what differentiates those with grievances who move to ideation from those who do not, we note that, as shown in Table 3, this sample of public mass murderers was under a substantial amount of stress in a variety of areas, from work and finances to relationships and anger management, suggesting that these strains may be relevant to the differentiation.

Many research opportunities concerning leakage remain. The present study did not contain mass murder events that were primarily IPV, gang/organized crime related, or with more than one offender, limiting the generalizability of the findings, and indicating areas for similar study. Also, the approach taken by this study could also be applied to other related groups of targeted violence offenders, including the groups previously assessed for the prevalence of leakage. Ideally, future efforts will also address the issue of false positives - namely, comparing cases of targeted violence and leakage with instances where there was leakage but no targeted violence. 


\section{References}

Calhoun, T., \& Weston, S., (2003). Contemporary threat management. San Diego: Specialized Training Services.

Dietz, P. E., \& Martell, D. (2010). Commentary: Approaching and stalking public figures- a prerequisite to attack. Journal of the American Academy of Psychiatry and the Law, 38, 341-348.

Drysdale, D., Modzeleski, W., and Simons, A. (2010). Campus Attacks: Targeted Violence Affecting Institutions of Higher Education. U.S. Secret Service, U.S. Department of Homeland Security, Office of Safe and Drug-Free Schools, U.S. Department of Education, and Federal Bureau of Investigation, U.S. Department of Justice. Washington, D.C., 2010.

Duwe, G. (2000). Body-count journalism: The presentation of mass murder in the news media. Homicide Studies, 4, 364-399.

Duwe, G. (2004). The patterns and prevalence of mass murder in twentieth century America. Justice Quarterly, (21)4, 729-759.

Duwe, G. (2005). A circle of distortion: The social construction of mass murder in the United States. Western Criminology Review, 6 (1), 59-78.

Federal Bureau of Investigation (2005). Serial Murder: Multidisciplinary Perspectives for Investigators. Behavioral Analysis Unit, National Center for the Analysis of Violent Crime.

Fein, R. A., Vossekuil, B. (1999). Assassination in the United States: An operational study of recent assassins, attackers, and near-lethal approachers. Journal of Forensic Sciences, 44(2), 321-333.

Fox, J. A., \& Levin, J. (1998). Multiple homicide: Patterns of serial and mass murder. In M. Tonry (Ed.), Crime and Justice: A Review of Research, 23 (pp. 407-455). Chicago: University of Chicago Press.

Fox, J. A., \& Levin, J. (2003). Mass murder: An analysis of extreme violence. Journal of Applied Psychoanalytic Studies, 5, 47-64.

Gill, P., Horgan, J., \& Deckert, P. (2014). Bombing alone: Tracing the motivations and Antecedent behaviors of lone actor terrorists. Journal of Forensic Sciences, (59), 2, 425 435.

Hempel, A. G., Meloy, J. R., \& Richards, T.C. (1999). Offender and offense characteristics of a nonrandom sample of mass murderers. Journal of the American Academy of Psychiatry and the Law, 27, 213-225.

Holmes, R. M., \& Holmes, S. T. (1992). Understanding mass murder: A starting point. Federal Probation, 56, 53-60.

Horgan, G., Gill, P., Bouhana, N., Silver, J., \& Corner, E. (2016), Across the universe? A comparative analysis of violent behavior and radicalization across three offender types 
with implications for criminal justice training and education. U.S. Department of Justice, National Institute of Justice.

James, D. V., Mullen, P., Meloy, J. R., Pathe, M., Farnham, F., Preston, L., \& Darnley, B. (2007). The role of mental disorders in attacks on European politicians, 1990-2004. Acta Psychiatra Scandinavica, 116, 334-344.

James, D.V., Mullen, P., Pathe, M., Meloy, J.R., Farnham, F., Preston, L., \& Darnley, B., (2008). Attacks on the British Royal Family: The role of psychotic illness. Journal of the American Academy of Psychiatry and the Law, 36, 59-67.

Krouse, W., \& Richardson, D. (2015). Mass murder with firearms: Incidents and victims, 19992013. Congressional Research Service. Retrieved from https://fas.org/sgp/crs/misc/ R44126.pdf

Lankford, A. (2012). A comparative analysis of suicide terrorists and rampage, workplace and school shooters in the United States from 1990 to 2010. Homicide Studies, 17(3), 255-274.

Lankford, A. (2015). Mass murderers in the United States: predictors of offender deaths. The Journal of Forensic Psychiatry \& Psychology, (July), 1-15. http://doi.org/10.1080/14789949.2015.1054858.

Madfis, E. (2014). Triple entitlement and homicidal anger: An exploration of the intersectional identities of American mass murderers. Men and Masculinities, 17(1), 67-86.

Meloy, J. R., Hempel, D. O., Gray, T., Mohandie, K., Shiva, A., \& Gray, T. (2001). Offender and offense characteristics of a nonrandom sample of adolescent mass murderers. Journal of the American Academy of Child and Adolescent Psychiatry, 40, 719-728.

Meloy, J. R., Hoffman, J., Roshdi, K., Glaz-Ocik, J., \& Guldimann, A., (2014). Warning behaviors and their configuration across various domains of targeted violence. In J. Meloy, \& J. Hoffman (Eds), International Handbook of Threat Assessment (pp. 3953). Oxford: Oxford University Press.

Meloy, J. R., \& O'Toole, M. E. (2011). The concept of leakage in threat assessment. Behavioral Sciences and the Law. doi:10.1002/bsl.986.

Newman, K., Fox, C., Roth, W., Mehta, J., \& Harding, D. (2004). Rampage: The social roots of school shootings. New York: Basic Books.

O'Toole, M. E. (2000). The school shooter: A threat assessment perspective. Quantico, VA: Critical Incident Response Group, National Center for the Analysis of Violent Crime.

Peete, T. A., Padgett, K. G., \& York, T. S. (1997). Debunking the stereotype: An examination of mass murder in public places. Homicide Studies, 1, 317-337.

Schmidt, A. P., \& Jongman, A. I. (1988). Political terrorism. A Research Guide to Concepts, Theories, Databases and Literature, Amsterdam and New Brunswick. 
Vossekuil, B., Fein, R., Reddy, M., Borum, R., \& Modzeleski, W. (2004). The final report and findings of the safe school initiative: Implications for the prevention of school attacks in the United States. Washington, DC: U.S. Secret Service and the U.S. Department of Education.

Warren, L. J., Mullen, P. E., \& Ogloff, J. R. P. (2011). A clinical study of those who utter threats to kill. Behavioral Sciences \& the Law, 29, 141-154. http://doi.org/10.1002/bsl. 